\title{
JOHN RAWLS: A RAZOABILIDADE COMO DEMARCAÇÃO DE OBJETIVIDADE
}

\author{
John Rawls: Reasonability as a Demarcation of Objectivity
}

\author{
Elnora Gondim \\ Tiago Tendai Chingore \\ Universidade Federal do Piauí \\ Universidade Licungo \\ elnoragondim@yahoo.com.br \\ ttendaigamachingore@gmail.com
}

\section{Resumo:}

na teoria tardia rawlsiana a objetividade é avaliada pelo parâmetro da razoabilidade. No entanto, para chegar a tal constatação, Rawls percorreu um longo caminho. De Uma Teoria da Justiça até $O$ Liberalismo Político muitos escritos favoreceram para o seu desenvolvimento teórico, onde o razoável tende a ter prioridade em relação ao racional, embora ambos sejam complementares. Tal aspecto é visto, primordialmente, em Posição Original garantindo a autonomia das partes em um sentido político. Aqui convém ressaltar que a razoabilidade não se relaciona à uma teoria da verdade, mas, somente, ao senso de justiça, em uma situação concreta, na qual as noções de pessoa e sociedade são compartilhadas e presentes em uma cultura pública.

\section{Palavras-chave:}

objetividade, Rawls, razoabilidade, posição original, liberalismo político

\begin{abstract}
:
In the late Rawlsian theory objectivity is evaluated by the reasonability parameter. However, to arrive at such a finding, Rawls has come a long way. From $A$ Theory of Justice to Political Liberalism many writings favored their theoretical development, where the reasonable tends to take priority over the rational, although both are complementary. This aspect is seen primarily in the Original Position, guaranteeing the autonomy of the parties in a political sense. It should be noted here that reasonableness is not related to a theory of truth, but only to a sense of justice, in a concrete situation, in which the notions of person and society are shared and present in a public culture.
\end{abstract}

Keywords:

objectivity, Rawls, reasonableness, original position, political liberalism 


\section{INTRODUÇÃO}

No libro Uma Teoria da Justiça, Rawls enfatiza o procedimento da posição original como um mecanismo de representação para alcançar objetividade. Após críticas, como por exemplo, o texto Rawls on Justice (1989), de Thomas Nagel, que mostra a dificuldade da posição original em se tratando da relação entre às concepções de bem e a questão da objetividade, argumentando que o véu de ignorância não é o bastante para garantir a imparcialidade das partes no momento da escolha dos princípios, é de se pressupor que Rawls escreve $O$ Liberalismo Político como uma forma de corrigir inconsistência vista em Uma Teoria da Justiça. Nele a concepção de justiça é política e a questão da objetividade, a qual será tratada aqui, muda a sua ênfase. Aqui é conveniente ressaltar que entre TJ e LP há uma démarche. Isso significando que as mudanças de uma obra para a outra não aconteceram abruptamente, mas por meio de rupturas e continuidades. Para tanto, Rawls publica os textos The Independence of Moral Theory (1975) e O Construtivismo Kantiano na Teoria Moral (1980).

\section{OBJETIVIDADE E UMA TEORIA DA JUST/ÇA}

Sobre a questão da objetividade, em Uma Teoria da Justiça, Rawls afirma que, em inúmeras vezes, a solidez das atitudes morais é questionada em virtude de suas origens psicológicas, tal fato ocorre quando se pensa que elas nasceram em situações que podem ser influenciadas pela submissão à autoridade. Isso leva à reflexão sobre a possibilidade de sua rejeição. E Rawls pergunta: "Por que não deveríamos julgá-las simplesmente como convulsões neuróticas?" (Rawls, 2002: p. 572). A resposta de Rawls é relacionada ao fato de que os membros, na sociedade bem-ordenada, têm características desenvolvidas tais como: o sentimento de justiça, o entendimento da moralidade dos princípios e a pressuposição de que a própria educação moral foi regulada pelos princípios do justo e da justiça. (Rawls, 2002: p. 573). Assim sendo, os processos psicológicos, que originam o senso moral, estão conforme princípios escolhidos em condições equitativas, pois os membros de uma sociedade-bemorganizada, ao concordarem com os princípios, concomitantemente, relaciona-os às suas condutas.

Nessa perspectiva, "O senso de justiça de uma pessoa não é um mecanismo psicológico compulsivo, instalado astutamente por aqueles que detém a autoridade." (Rawls, 2002: p. 573). Como, também, o processo educativo "não é uma criação dos sentimentos morais adequados" (Rawls, 2002: p. 574). Muito pelo contrário, os membros de uma sociedade bem-organizada agem de forma autônoma segundo às suas características de seres racionais livres e iguais com uma educação para a autonomia. Isso significa dizer que " todos saberão por que adotariam princípios de justiça". (Rawls, 2002: p. 574). 
Nesse sentido, segundo a justiça como equidade como uma interpretação kantiana, Rawls afirma que, em sociedade bem ordenada, se alguém seguir os princípios de justiça isso significa que a pessoa age de forma autônoma, porquanto expressa a natureza de seres racionais, livres e iguais.

Com base no acima exposto, é conveniente ressaltar que há uma relação intrínseca entre objetividade, autonomia, liberdade e razão, onde isso é expresso no mecanismo de representação chamado de posição original. Em última análise, a posição original é responsável pela objetividade dos princípios de justiça tendo, como consequência, a possibilidade de um acordo.

No entanto, em Uma Teoria da Justiça é acentuado o caráter racional para que os cidadãos tenham autonomia e, para não se ter uma concepção heterônoma, há uma preocupação em não se imiscuir a escolha dos princípios com circunstâncias concretas, pois os juízos particulares não devem ser levados em consideração e, sendo assim, a autonomia dos cidadãos não é violada como, também, nela não pode ser considerado algo como uma "[...] mera colisão de vontades que se autojustificam" (Rawls, 1997: p 579). Desse modo, Rawls afirma que da interpretação que ele faz da concepção de justiça kantiana deriva o princípio de liberdade e a sua prioridade. Nesse sentido, ele diz que a força da doutrina kantiana deve-se aos seguintes aspectos:

1. na ideia de que os princípios morais são objetos de uma escolha racional, onde eles definem a lei moral que os homens objetivam para reger sua conduta em uma comunidade ética;

2. a legislação moral deve ser acatada caracterizando os homens como seres racionais, livres e iguais, isto é, uma pessoa age de modo autônomo quando escolhe princípios que denotem a sua natureza de livre, racional e igual.

Assim, Rawls afirma que a justiça como equidade é uma teoria de interpretação da doutrina kantiana nos seguintes aspectos:

1. o véu de ignorância priva as pessoas de obterem uma escolha dos princípios de forma heterônoma;

2. as pessoas escolhendo e agindo conforme os princípios de justiça de forma autônoma, elas expressam a sua própria natureza;

3. os princípios de justiça apresentam-se como imperativos categóricos, onde as partes não agem de forma heterônoma, isto é, não se deixando levar por desejos particulares, mas, pelo contrário, aspiram, apenas, aquilo que é racional, geral, independente dos outros desejos e aplicado a qualquer um, isto é, desejam os bens primários;

4. o desinteresse mútuo, pois permite que a escolha dos princípios seja livre.

Nessa perspectiva, segundo Rawls, ele ampliou a noção kantiana de autonomia, porquanto a parte que falta no argumento de Kant é aquela que diz respeito ao conceito de expressão. Em contrapartida, a posição original aponta argumentos que dizem quais princípios seriam escolhidos por pessoas racionais, livres e iguais. Assim 
sendo, a posição original é um nôumeno perante o mundo, onde as partes expressariam sua liberdade de escolha como membros de uma sociedade e ela não seriam um artifício nem transcendente nem transcendental.

Em outras palavras, na posição original, os membros entram em um acordo sobre uma determinada concepção de justiça e, para tanto, assumem a responsabilidade pela mesma. "Caso contrário, a autonomia provavelmente levará a uma mera colisão de vontades que se autojustificam e a objetividade conduzirá à uma adesão a um sistema consistente, mas idiossincrático." (Rawls, 2002: p. 578). E Rawls exemplifica:

Um tirano pode manifestar em alto grau esses atributos, e fazer exercer um certo encanto, sem se deixar iludir com pretextos políticos e desculpas de ocasião. É impossível construir uma visão moral apenas a partir dessas virtudes; sendo virtudes formais, elas são, em certo sentido, secundárias. ( Rawls, 2002: p. 579).

O autor de Uma Teoria da Justiça conclui afirmando que em uma sociedade bemorganizada os indivíduos, em posição original, têm uma referência direta com a questão da objetividade e da autonomia, ou seja:

Os indivíduos que, ao refletirem sobre como essas disposições foram adquiridas, tenham quaisquer dúvidas a respeito da solidez de seus sentimentos morais, podem eliminá-las observando que as suas convicções correspondem aos princípios que seriam escolhidos na posição original ou, se não for esse caso, revisando seus julgamentos para que elas possam manter essa correspondência. (Rawls, 2000: p. 579)

Portanto, em Uma Teoria da Justiça, Rawls considera a objetividade como algo relacionado à racionalidade, à interpretação kantiana de autonomia e à posição original.

\section{A QuestaO DA OBJetIVIDADE NO ARTIGO THE INDEPENDENCE OF MORAL THEORY (1975)}

No artigo de 1975, Rawls verificou que a teoria moral é independente da epistemologia, da filosofia da linguagem e da filosofia da mente, afirmando:

A independência da teoria moral da epistemologia surge do fato de que o procedimento do equilíbrio reflexivo não pressupõe que haja uma concepção moral correta. (..) e não pressupõe a existência de verdades morais objetivas. Mesmo que todos alcancem um amplo equilíbrio reflexivo, muitas concepções morais contrárias ainda podem ser defendidas. Na verdade, existem muitas possibilidades. (Rawls, 1999: p.290) $)^{1}$

\footnotetext{
1 "The independence of moral theory from epistemology arises from the fact that the procedure of reflective equilibrium docs not assume that there is one correct moral conception. (...) and does not presuppose the existence of objective moral truths. Even
} 
Conforme a citação acima, Rawls diz que a independência da teoria moral da epistemologia decorre do fato de que o procedimento de equilíbrio refletivo considera várias concepções diferentes e não pressupõe uma concepção moral correta nem verdades morais objetivas.

Nessa perspectiva, no texto de 1975, Rawls afirma que as verdades objetivas não são levadas em consideração, porque o equilíbrio reflexivo requer que o agente faça revisões contínuas, também, nem a epistemologia e nem a metafísica foram capazes de fundamentar morais objetivas. Por esse motivo, a teoria moral não pondera questões referentes às verdades objetivas nas concepções morais, pois as pessoas, em suas vidas diárias, têm valores morais e são influenciadas por eles. Por causa disso, a teoria moral não deve ser relacionada com as verdades morais. Ela relaciona-se com o bem e com a dignidade moral.

No artigo The Independence of Moral Theory (1975), Rawls explicita a ideia de equilíbrio reflexivo. Ele pode ser visto como (amplo) wide ou (restrito) narrow. Nesses termos, a ênfase dada por Rawls ao equilíbrio reflexivo amplo em The Independence of Moral Theory está relacionada à explicação da independência da teoria moral frente à epistemologia, a filosofia da linguagem e a filosofia da mente e, para tanto, Rawls afirma:

Agora meu pensamento é este: muita da teoria moral é independente das outras partes da filosofia. A teoria da linguagem e da epistemologia e a filosofia da mente, podem frequentemente contribuir muito pouco. ${ }^{2}$

Assim, no artigo supradito, a teoria moral é parte da filosofia moral e tem o significado de ser o estudo das concepções substantivas morais, ou seja, é o modo segundo o qual as noções básicas (do direito, do bem e dos valores morais) podem ser harmonizadas para formarem diferentes estruturas morais. Ela é independente da epistemologia, pois, como mostra a história da filosofia moral, a noção de verdade objetiva moral é problemática.

No entanto, Rawls argumenta que as pessoas são influenciadas por convicções morais. Essas podem, então, ser um foco de estudos. Partindo desse pressuposto, Rawls investiga a teoria moral no sentido de levar em conta as concepções morais substantivas que as pessoas consideram, colocando entre parêntesis a questão sobre a verdade objetiva moral. Assim, tentará descobrir princípios combinando os julgamentos considerados e as convicções das pessoas em equilíbrio reflexivo. Nesse caso, os julgamentos particulares sobre ações particulares não têm informação relevante sobre concepções morais. No entanto, as pessoas têm julgamentos considerados em todos os níveis de generalidade que estão acima das situações particulares. Assim, os julgamentos particulares não têm o mesmo status atribuído aos julgamentos da percepção em teorias do conhecimento.

should everyone attain wide reflective equilibrium, many contrary moral conceptions may still be held. In fact, there are many possibilities." (Rawls, 1999: p.290)

2 "Now my thought is this: much of moral theory is independent from the other parts of philosophy. The theory of meaning and epistemology, metaphysics and the philosophy of mind, can often contribute very little..." (Rawls, 1999: p. 225). 
Portanto, a independência da teoria moral da epistemologia provém do fato de que o procedimento do equilíbrio reflexivo não assume que existe uma necessidade para se descobrir o método verdadeiro, e Rawls afirma:

A independência da teoria moral da epistemologia surge do fato de que o procedimento do equilíbrio reflexivo não pressupõe algo para descobrir o método verdadeiro de determinar o que devemos fazer; em vez disso, ele deseja expor, de uma posição neutra e tão imparcialmente quanto possível, os diferentes métodos encontrados na consciência moral da humanidade em geral e nos sistemas históricos familiares. ${ }^{3}$

Nessa perspectiva, a independência da teoria moral frente à epistemologia é em face da utilização do procedimento do equilíbrio reflexivo amplo (wide). Como dito anteriormente, Nele não é pressuposta a existência de verdades morais objetivas. Em outras palavras, o interesse de Rawls reside no fato de saber quais concepções as pessoas afirmam quando elas alcançam o equilibrio reflexivo amplo (wide). Por conseguinte, ele investiga quais princípios as pessoas conhecem e aceitam as consequências quando elas têm uma oportunidade para considerarem outras concepções plausíveis e para estabelecerem seus fundamentos.

Assim sendo, para o equilíbrio reflexivo amplo (wide) determinar um princípio é julgar se ele é conforme com as convicções consideradas. No entanto, no equilíbrio reflexivo amplo (wide) não se tem somente que ponderar sobre o ajustamento entre as convicções morais, mas também considerar este ajustamento garantido quando testadas por considerações racionais, ou seja, as pessoas têm que considerar os julgamentos em todos os níveis de generalidade, por meio de princípios para formar e abstrair condições sobre concepções morais. Então, o objetivo disso é saber como as pessoas ajustam suas várias convicções em um esquema coerente, revisando convicções, reforçando e expandindo outras, supondo que uma sistemática organização pode ser fundada. Portanto, no procedimento do equilíbrio reflexivo não existe julgamento que seja imune à revisão.

Assim sendo, o equilíbrio reflexivo wide é aquele em que as pessoas têm que considerar os julgamentos em todos os níveis de generalidade, por meio de princípios para formar e abstrair condições sobre concepções morais. Isso objetiva saber como as pessoas ajustam suas várias convicções em um esquema coerente, revisando algumas crenças, reforçando e expandindo outras, supondo que uma sistemática organização pode ser fundada, onde os julgamentos não são imunes à revisão. No texto de 1975, o equilíbrio reflexivo wide é visto de forma mais explícita e, por meio dele, é afirmada a questão da objetividade no momento da eleição dos princípios de justiça.

3 "...The independence of moral theory from epistemology arises from the fact that the procedure of reflective equilibrium does not assume that there is one that he wants to put aside the urgency we feel to discover the true method of determining what we ought to do; instead he wishes to expound, from a neutral position and as impartially as possible, the different methods found in the moral consciousness of humankind generally, and worked up into the familiar historical systems...". (Rawls, 1999: pp. 225- 226). 


\section{A questão da Objetividade e O CONStRutivismo Kantiano Na teORIA} MORAL (1980)

Continuando o estudo sobre a questão da objetividade, é bom ressaltar que Rawls escreve um artigo intitulado O Construtivismo Kantiano em Teoria Moral (1980), nele ele afirma que "gostaria de examinar a maneira pela qual uma doutrina kantiana interpreta a noção de objetividade no sentido de um ponto de vista social" (Rawls, 2000: p. 111). E complementa afirmando que a objetividade significa que os princípios de justiça não são considerados verdadeiros, mas razoáveis e que, são dessa forma, por causa da concepção de pessoa, livre, igual e autônoma. Nessa perspectiva, Rawls afirma: "a ideia kantiana de autonomia exige que não possa existir uma ordem de objetos tal que determinasse os princípios primeiros do justo e da justiça para pessoas morais, livres e iguais." (Rawls, 2000a: p. 119).

Assim, em tal doutrina, a seleção dos princípios ocorre por meio dos procedimentos sintéticos a priori relacionados à razão prática. Em outras palavras, na teoria rawlsiana a concepção de pessoa é central. Ela é capaz de determinar o conteúdo dos princípios, onde a deliberação desses ocorre por meio das faculdades de reflexão e julgamento através de um acordo público. "Assim uma concepção de justiça é feita para satisfazer às exigências práticas da vida social e para fornecer uma base pública que permita aos cidadãos justificarem as suas instituições comuns uns aos outros" (Rawls, 2000루: p. 122).

Nesse sentido, ele adiciona algumas ideias àquelas de Uma Teoria da Justiça, concebendo os agentes como seres que fazem parte de um processo de construção, onde esses são movidos, apenas, por seus interesses superiores, isto é, aqueles interesses de primeira ordem que impelem os agentes a efetivarem a sua personalidade moral, desenvolvendo e exercendo as suas faculdades morais, onde a sociedade é considerada um bem que permite a concretização desses interesses superiores.

Assim, Rawls amplia a sua ideia de autonomia e afirma que os parceiros em posição original são considerados como pessoas morais, livres e iguais, onde isso significa dizer que eles têm uma concepção do bem e um senso de justiça. A liberdade, entendida dessa forma, expressa que as pessoas, enquanto representantes em posição original, consideram aquilo que é de interesse superior submetido à regra da razão, exprimindo, assim, sua autonomia pelo fato delas seguirem princípios razoáveis e racionais. No entanto, isso significa objetividade, porquanto essas pessoas não têm uma intenção última particular, ao contrário, dispõem como conduta apreciar e revisar seus fins tendo como parâmetro considerações razoáveis.

\section{RAWLS: AUTONOMIA E RAZOABILIDADE}

Nem sempre a concepção do razoável se fez presente nas obras de Rawls. Como exemplo, o filósofo de Harvard corrige um comentário feito por ele nos parágrafos três e nove da Teoria da Justiça, TJ, nos quais asseverava que a teoria da justiça é parte da teoria da escolha racional (Rawls, 2002: p. 115). Em O Liberalismo Político, Rawls ampliou a noção de autonomia. 
Nessa perspectiva, ele consegue enfatizar o aspecto construtivista da sua teoria, fornecendo uma interpretação de seu pensamento a partir da explicação da característica do político para as suas principais ideias, adotando elementos que no processo de construção dos princípios de justiça são justificados como algo que está implícito na cultura das sociedades democráticas.

Dessa maneira, ele estende o princípio da autonomia moral, visto em Uma Teoria da Justiça, ao campo do político. Assim, ele diferencia a autonomia racional da autonomia plena e afirma ser esta última um ideal político, uma parcela constituidora das sociedades bem-ordenadas Nesse sentido, Rawls reconhece que, contrariamente a Uma Teoria da Justiça, não se deve considerar a teoria da justiça como equidade como uma teoria da decisão racional, porquanto, somente, isso não basta e não é o essencial. O que é importante é modelar as convicções bem ponderadas, fazendo com que os cidadãos compatibilizem sua liberdade e igualdade de uma forma justa em uma sociedade democrática constitucional.

Dessa forma, Rawls estende o princípio da autonomia moral ao campo do político e, assim, expressa algo decisivo para o seu problema fundamental que é aquele de decidir sobre o tipo de sociedade em que as concepções do bem e do senso de justiça podem ser desenvolvidas e aplicadas. Porquanto, o construtivismo de Rawls, através do seu ideal de autonomia política, modela as concepções de pessoa e sociedade, onde os agentes racionais e razoáveis são sujeitos a restrições relativas à razoabilidade Em LP, Rawls faz a pergunta sobre o que distingue o razoável do racional; começa a explicação mostrando como no dia-a-dia isto é visto imediatamente e exemplifica: “... Dizemos: sua proposta era perfeitamente racional, dadas suas condições privilegiadas de barganha, mas, apesar disso, não tinha nada de razoável, chegava a ser ultrajante..." (Rawls, 2000: p. 92).

Mediante o exemplo acima referido, Rawls expõe que a distinção entre o racional e o razoável remonta a Kant e compara o primeiro termo ao imperativo categórico e o segundo ao hipotético, porquanto um ocupa-se com a razão prática pura e o outro representa a razão prática empírica. No entanto, Rawls afirma que, embora mantenha a diferença, ele próprio atribui ao razoável um sentido restrito; o associa às disposições de: (i) propor e sujeitar-se a termos equitativos de cooperação; (ii) reconhecer os limites do juízo, aceitando, assim, suas consequências.

Nesse sentido, o termo razoável encontra-se relacionado ao princípio de motivação moral de T.M. Scanlon o qual afirma que as pessoas têm um desejo básico de serem capazes de justificar as suas ações perante os outros com argumentos razoáveis. Este desejo é aquele de encontrar princípios que outros, motivados da mesma forma, não poderiam rejeitar se fossem razoáveis. Assim, as pessoas podem não ser movidas por um bem comum, no entanto elas desejam um mundo em que todos cooperem com todos em uma reciprocidade, de modo que cada pessoa se beneficie juntamente com as outras. Em contrapartida, quando elas não se propõem a obedecer nem a sugerir princípios ou critérios relacionados aos termos equitativos de cooperação, não são consideradas razoáveis.

A ideia de razoável é diferente da ideia de racional. Este termo se aplica a um agente único dotado das capacidades de julgamento e de deliberação ao buscar seus 
interesses, seja ele um indivíduo ou uma pessoa jurídica. Os agentes racionais não têm uma forma de sensibilidade moral subjacente em relação ao desejo de se engajar na concepção equitativa.

As pessoas racionais não têm o que Kant chama de predisposição à personalidade moral. Assim, esse agente compreende o significado da lei moral, seu conteúdo conceitual, mas não é motivado por ela: para um agente assim, trata-se apenas de uma ideia curiosa.

Nesse sentido, na justiça como equidade o razoável e o racional são ideias distintas e independentes, porquanto o justo não é derivado do bem. Contudo, na ideia de cooperação equitativa, essas duas noções são complementares; uma tem como significado o fato das pessoas terem a capacidade de senso de justiça e a outra encerra uma capacidade para terem uma concepção do bem. Dessa forma, o razoável e o racional são inseparáveis enquanto ideias complementares em relação à cooperação equitativa.

Em contrapartida, tanto a ideia do razoável quanto à do racional ambas mantém características peculiares. Sendo assim, o razoável tem uma forma de público e o racional não a tem. Através do razoável os indivíduos são iguais no mundo público dos outros e podem propor, aceitar e dispor termos equitativos de cooperação entre eles. Contudo, o razoável não é sinônimo de altruísmo nem de egoísmo, pois:

A sociedade razoável não é uma sociedade de santos nem uma sociedade de egoístas. É a parte do nosso mundo humano comum, não de um mundo que julgamos de tanta virtude que acabamos por considerá-lo fora do nosso alcance. No entanto, a faculdade moral que está por trás da capacidade de propor, ou de aceitar, e, depois, de motivar-se a agir em conformidade com os termos eqüitativos de cooperação por seu próprio valor intrínseco é, mesmo assim, uma virtude social essencial (Rawls, 2000: p. 98).

Por conseguinte, a autonomia da teoria rawlsiana é de tal modo que não pode ser considerada como verdadeira, porque isto levaria a uma fundamentação metafísica ou epistemológica, aspectos característicos das doutrinas compreensivas.

De acordo com isso, a objetividade implica que os princípios mais razoáveis para os agentes relacionam-se com o fato de que eles são pessoas livres e iguais e membros cooperantes de uma sociedade democrática.

Nessa perspectiva, a concepção de objetividade tem como elementos essenciais os seguintes itens:

1. estabelecer uma estrutura pública de pensamento suficiente para que o conceito de julgamento seja aplicado e para que se chegue às conclusões com base em razões e evidências após discussão e reflexão;

2. especificar um conceito de julgamentos corretos como razoáveis que sejam julgamentos que se baseiam na preponderância de razões especificadas pelos princípios de direito e justiça, resultantes de um procedimento que formula corretamente os princípios da razão prática conjugadas às concepções apropriadas 
de sociedade e pessoa. Nesse sentido, eles devem especificar uma ordem de razão de maneira estabelecida por seus princípios e critérios e devem atribuir esta razão a agentes como razões que eles possam pesar e pelos quais podem guiar-se em determinadas circunstâncias. Na justiça como equidade, o ponto de vista objetivo de qualquer agente específico é diferenciado e tem que ter uma interpretação do que seja a concordância de julgamento entre agentes razoáveis, requerendo que sejam capazes de explicar as discordâncias de uma certa forma;

3. uma concepção moral e política pode ser considerada objetiva somente quando estabelece uma estrutura razoável de pensamento, argumentação e julgamento;

Assim, os elementos essenciais para uma concepção de objetividade devem estabelecer uma estrutura pública suficiente para que o conceito de julgamento possa ser aplicado e para que seja possível chegar a conclusões com base em razões e evidências mutuamente reconhecidas. Nesse sentido, a característica do julgamento é fazê-lo ser razoável, onde a ordem das razões dadas por seus princípios seja transmitida aos agentes como razões às quais eles devem dar a devida prioridade distinguindo as razões que têm de acordo com seu próprio ponto de vista.

Logo, o construtivismo afirma que a objetividade da razão prática é independente da teoria causal do conhecimento e existem concepções diferentes de objetividade para a razão teórica e razão prática.

Em relação à razão prática, esta diz respeito à produção de objetos de acordo com uma concepção desses objetos, ou seja, como indivíduos razoáveis e racionais, devemos construir adequadamente os princípios do direito e da justiça que especificam a concepção dos objetos que devem produzir e orientar a conduta publica pela razão prática.

Para as exigências da objetividade elas devem ter condições de reduzir as diferenças, nos aproximando de um acordo à luz do que se vê como princípios e critérios compartilhados da razão prática.

Desse modo, pode-se dizer que uma concepção política de justiça produz razões objetivas, politicamente falando, quando as pessoas razoáveis e racionais acabam por endossar ou reduzir suas diferenças em relação às convicções políticas.

Uma convicção política é objetiva quando há razões especificadas por uma concepção política mutuamente razoável e reconhecível (satisfazendo os elementos essenciais) suficientes para convencer todas as pessoas razoáveis de que ela é razoável. Nesse sentido, os agentes devem ser capazes de explicar a impossibilidade de convergência dos julgamentos por meio de coisas como os limites de juízo. Neste ponto é conveniente lembrar que entre as virtudes políticas encontram-se a tolerância, o respeito mútuo, senso de equidade e civilidade.

\section{CONSIDERAÇÕES FINAIS}

O tema da objetividade pode ser visto no desenvolvimento da teoria rawlsiana desde a sua obra magna, Uma Teoria da Justiça, cuja abordagem é restrita à posição original e à questão da racionalidade. Tal desdobramento culmina com a publicação 
do libro $O$ Liberalismo Político. Em tal texto a questão é avaliada por meio do parâmetro político, isto é, nas sociedades plurais, democráticas, por meio da razão prática pública, do equilíbrio reflexivo, levando em consideração o razoável e o nãorazoável. No entanto, o razoável não é relacionado à uma teoria da verdade, mas arrolado com a finalidade de algo ser constituído a partir do que é justo, em uma situação concreta, na qual as noções de pessoa e sociedade são compartilhadas e presentes no âmbito de uma cultura pública que possibilita o consenso sobreposto.

No entanto entre os libros Uma Teoria da Justiça (1971) e O Liberalismo Político (1996), o tema da objetividade é ampliado e engendrado culminando com o texto de 1996. Como amostragem, para Rawls culminar com o escrito de 1996, temos os artigos The Independence of Moral Theory (1975) e O Construtivismo Kantiano em Teoria Moral (1980). No escrito de 1975, Rawls diz não haver, em se tratando de teoria moral, verdade objetiva. Para provar isso, explicita a ideia de equilíbrio reflexivo amplo. Com tal método, as convicções morais podem ser harmonizadas considerando os julgamentos em todos os níveis de generalidade, onde os julgamentos particulares sobre ações particulares não têm informação relevante sobre concepções morais. Por conseguinte, sendo utilizado de uma forma ampla e razoável, o método do equilíbrio reflexivo garante objetividade à teoria.

No texto de 1980, por sua vez, a objetividade significa que os princípios de justiça não são considerados verdadeiros, mas razoáveis e que, são dessa forma, por causa da concepção de pessoa, livre, igual e autônoma. Assim sendo, os agentes fazem parte de um processo de construção movidos por seus interesses superiores, desenvolvendo e exercendo as suas faculdades morais por meio da autonomia política. O acordo, em forma de construção, é feito para atender às vindicações da vida social, em uma base pública que permita aos cidadãos justificarem as suas instituições comuns uns aos outros.

Portanto, quando Rawls fala de objetividade, no livro $O$ Liberalismo Político, ele não o faz sem um desenvolvimento anterior da referida temática. Sendo assim, a teoria rawlsiana amplia a ideia tratada e procura estabelecer uma estrutura de pensamento segundo a qual se possa identificar os fatos que são relevantes de um ponto de vista apropriado e determinar seu peso enquanto razões. Há ideias que são possibilidades de construção de uma concepção política. Em outros termos, só se tem uma concepção política quando os fatos estão coerentemente ligados em entre si pelos conceitos e princípios aceitáveis para todos depois de cuidadosa reflexão. Nesse sentido, para o construtivismo político o conceito de razoável é suficiente para se ter certa objetividade em seus resultados, garantindo com isto, um caráter político e não-metafísico, em uma sociedade plural, por meio da razão pública prática, do equilíbrio reflexivo decorrendo um consenso sobreposto. 
REFERÊNCIAS

AUDARD, Catherine (2006). Cidadania e democracia deliberativa. Porto Alegre: EDIPUCRS.

DANIELS, Norman (1979). Wide reflective equilibrium and theory acceptance in ethics. The Journal of Philosophy, V. 76, N. 5.

DANIELS, Norman (1975). Reading Rawls. Oxford: Basil Blackwell.

HÖFFE, Otfried (2003). O Que é justiça? Porto Alegre: EDIPUCRS.

RAWLS, John (2002). Uma Teoria da Justiça. São Paulo: Martins Fontes.

RAWLS, John (2003). Justiça como equidade: uma reformulação. São Paulo: Martins Fontes.

RAWLS, John (2000). O Liberalismo político. São Paulo: Ática.

RAWLS, John (2000aㅡ). Justiça e democracia. São Paulo: Martins Fontes.

RAWLS, John (1999). Collected papers (org. Samuel Freeman). Cambridge: Harvard University Press.

SCANLON, T. M. (1989). "Rawls' theory of justice". In: DANIELS, Norman (Ed.) Reading Rawls. Stanford California: Stanford University Press.

SMITH, Paul (2009). Filosofia moral e política: principais questões, conceitos e teorias. São Paulo: Madras. 